\title{
A Korean Adaptation of the Tinnitus Magnitude Index: Validity and Reliability
}

\author{
Da-Hye Hwang ${ }^{1,2}$, Junghwa Bahng ${ }^{2}$ \\ ${ }^{1}$ Department of Otolaryngology, Hearing Clinic, Severance Eye \& ENT Hospital, Seoul, Korea \\ ${ }^{2}$ Department of Audiology and Speech Language Pathology, Hallym University of Graduate Studies, Seoul, Korea \\ 한국어판 이명규모지수의 타당도 및 신뢰도에 관한 연구 \\ 황 다 혜,2.방 정 화 ${ }^{2}$ \\ 세브란스 안이비인후과병원 이비인후과 청각검사실', 한림국제대학원대학교 청각언어치료학과 ${ }^{2}$
}

Purpose: The Tinnitus Magnitude Index (TMI) is a short tinnitus questionnaire that assesses the subjective perception of tinnitus loudness. Originally, Schmits et al. developed the TMI in English. This study aimed to determine the validity and reliability of a Korean translation of the TMI. Methods: A Korean version of the TMI was administrated 215 subjects reporting tinnitus. Construct validity was evaluated using the Tinnitus Handicap Inventory (THI). Puretone audiometry, speech audiometry, and tinnitogram were also assessed. Results: A significant and moderate correlation was found between the TMI and the THI-total scale. The TMI was the most significant correlated with the THI-functional subscale. The TMI also had high internal consistency reliability, confirming the questionnaire's stability. Conclusion: The results suggested that the Korean version of the TMI might be a valuable validity and reliability. The Korean version of TMl could be an effective tool to quantify the impact of tinnitus.

Key Words: Tinnitus, Questionnaire, Tinnitus magnitude index.

Received: March 20, 2018 / Revised: April 16, 2018 / Accepted: April 17, 2018

Correspondence: Junghwa Bahng, Department of Audiology and Speech Language Pathology, Hallym University of Graduate Studies, 427 Yeoksam-ro, Gangnam-gu, Seoul 06197, Korea

Tel: +82-70-8680-6933 / Fax: +82-2-3451-6618 / E-mail: bahng.jh@gmail.com

\section{INTRODUCTION}

이명은 청각적 또는 전기적 자극이 없는 상황에서 소리를 자 각하는 증상으로 전 세계의 성인 중 약 $5 \%$ 정도가 지속적인 이 명이 들리고, 약 1 3\%는 삶의 질에 영향을 줄 만큼 심각한 이 명을 겪고 있다(Hear-it, 2018). 이러한 이명을 진단하거나 평가 하는 보편적인 척도는 아직 확립되지 않았으며, 현재 임상에서 사용하고 있는 구조화된 자가 설문지는 이명을 겪고 있는 대상 자가 이명으로 인한 불만사항이 무엇인지 확인하는 용도로 사 용하고 있다(McCormack et al., 2016). 이명은 주관적인 소리 이므로 객관적 평가의 결과가 재활 혹은 치료에 있어서 많은 도움을 주지 못하며, 평가의 결과와 관계없이 주관적으로 이명 의 불편함과 감정적인 불편함을 현 상태의 평가와 이명 치료 전후 평가를 하는 것이 이명의 관리에 있어서 매우 중요하다.

이명의 원인은 청각 시스템의 말초 병변의 결과로 인한 대뇌
피질의 입력 오류의 결과라는 것은 보편적으로 많이 알려진 사 실이다. 만성통증 역시 이와 마찬가지로 말초 병변에 의한 다양 한 주관적인 감각으로, 이명과 만성통증은 많은 유사점을 가졌 다(Møller, 2007). 그 유사점은 수면장애, 특히 집중할 때의 인 지적 어려움, 직장이나 가정에서의 사회적 관계에 대한 어려움, 걱정, 좌절, 분노 같은 부정적 감정 반응 같은 것들이 있다 (Dobie, 2004; Meikle et al., 2008; Stouffer \& Tyler, 1990; Tyler \& Baker, 1983). 이러한 유사점으로 인하여 이명의 치료에 만성통증 완화를 위한 심리치료요법 등을 적용한다(Cima et al., 2011; Henry \& Wilson, 2000).

\section{인지-행동 조정 모델(Cognitive-behavioral mediation} therapy model, CBT)

만성통증 분야의 재활에 도입된 모델인 인지-행동 조정 모델 은 자제력(self-control)과 간섭(interference)이 통증의 매개 역 
할을 한다는 것을 입증하는 모델이다(Rudy et al., 1988). 이명 이 발생하게 되면 이명으로 인한 괴로움은 간섭(행동적 변화) 과 자제력 저하(인지적 변화)로 인해 일어나고, 이어서 우울 증 상을 유발할 수 있다. 하지만 이명으로 인한 심각성은 우울 증 상의 정도만으로는 설명할 수 없다. 인지-행동 조정 모델에 적 용하여 요약하면 통증이 직접적으로 바로 감정적 스트레스를 유발하는 것이 아니라, 통증은 인지적 변수를 거쳐 감정적 스 트레스를 가져온다. 물리적으로 같은 강도의 통증이라도 결과 적으로 환자가 느끼는 감정적 스트레스의 강도는 인지적 변수 에 따라 관계가 있으며, 이명의 정신적 고통은 이명의 규모 (magnitude), 개인의 성격적 특징에 모두 영향을 받으며, 그 관 계는 인지적 기능장애(이명에 관한 비극적인 생각, 잘못된 믿음) 에 의해 조정될 수 있다(Lee at al., 2004). 인지-행동 조정 모델 을 구조화하면 예측변수(predictor)가 반응(response)을 유발 하는데, 조정체(mediator)는 예측변수와 반응 사이에 위치하여 예측변수가 조정체를 거쳐서 반응을 유발하게 된다. 이때 조정 체는 인지와 행동적 변화를 의미하며, 따라서 인지와 행동적 변 화를 통해 같은 예측변수라도 다른 반응을 도출할 수 있다.

인지-행동 조정 모델을 이명에 적용시키면 각 항목은 다음과 같이 대입할 수 있다. 예측변수는 이명의 규모(magnitude), 조정 체는 재활에서 시행되는 이명의 중재(예를 들어 소리치료, 상담), 그리고 반응은 이명으로 인한 정신적 고통으로 대입할 수 있다. 이명의 규모는 이명으로 인한 정신적 고통을 유발하지만, 이명의 중재를 통해 정신적 고통은 변할 수 있는 것이다(Figure 1).

Searchfield et al.(2012)은 이명의 크기(loudness)는 이명을 탐지하는 정도에 영향을 주는 요소 중 하나일 뿐, 크기 단독으 로 이명의 심각성(severity)을 결정 지을 수 없다고 하였다. 이명 의 심각성은 집중도, 청각과 감정적 요소를 포함한 다양한 과정 을 통해 결정되며, 주관적으로 느끼는 이명의 가청도(audibility)

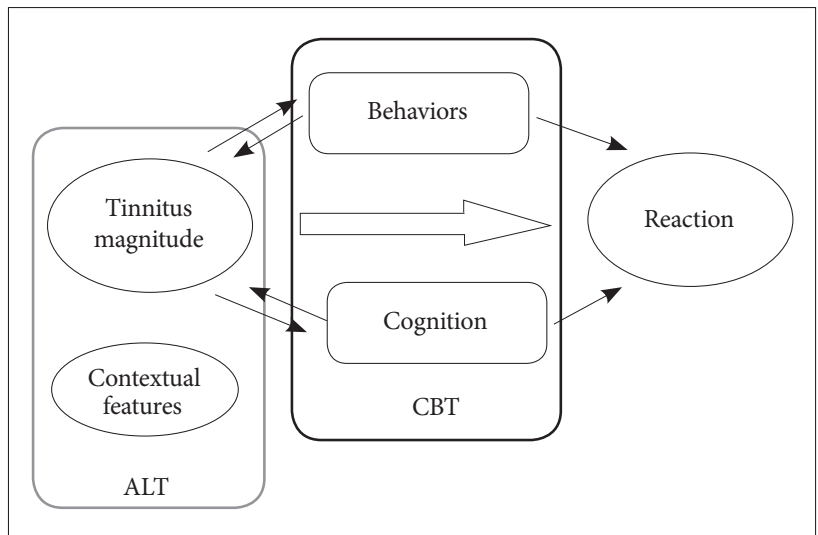

Figure 1. Model of behavioral cognitive mediation. Contextual features are personality, prior memory, arousal state, cognitive and psychological variables, etc. ALT: adaptation level theory, CBT: cognitive behavioral mediation therapy model.
를 적응수준이론(adaptation level theory, ALT)에 근거하여 이 명으로 인한 스트레스는 인지와 행동의 변화를 줄 수 있는 재활 로 정신적 고통이 줄어들 수 있는 가능성으로 설명 가능하다.

\section{적응수준이론(Adaptation level theory)}

적응수준이론은 환경에 따라 감각에 대한 인지가 달라질 수 있음을 설명하는 이론이다(Helson, 1964). 이명의 규모(magnitude)는 감각자극과 환경적 요인 사이의 관계를 통하여 달라질 수 있다. 즉, 이명의 규모는 독립적인 요소가 아니라 환경적 요 인, 예를 들어 주변 배경 소음, 심리적 요소, 인지적 요소 등에 따라 적응 수준(adaptation level)이 변하여 자각이 증가할 수 도 있고 감소될 수도 있다.

적응수준이론을 이명의 인지-행동 조정 이론에 적용하면, 적응수준이론의 주변 특징, 예를 들어 개인의 성격, 기억, 각성 상태, 인지와 정신적 변수 등이 이명 규모를 결정 짓는 데 중요 한 역할을 할 수 있음을 설명할 수 있다. 또한 적응수준이론을 통해 소리치료와 같은 이명 재활치료를 받으면 이명을 자각하 는 규모는 감소할 것이라고 예상할 수 있다. 따라서 적절한 이 명 중재가 들어가면 이명의 규모는 감소하여 이명의 반응 역시 감소하게 된다.

위의 두 이론을 적용시킬 경우, 이명의 자각은 이명의 반응과 연결되어 있으며 이명의 자각만을 물어보아도 이명의 주관적인 반응에 대하여 알 수 있게 된다. 현재 임상에서 사용하는 이명 평가의 척도는 자각(perception)과 이명에 대한 반응(reaction) 으로 나눌 수 있다. 자각은 이명의 크기와 같은 청각적 인지 특 성을 말하며, 심리음향검사로 측정된다. 이명에 대한 반응은 감 정적(정신적) 고통, 집중력 저하, 자제능력 저하, 수면방해와 같 은 삶의 질에 영향을 미치는 영역으로, 설문지를 통해 측정할 수 있다(Jun et al., 2015). 많은 설문지들이 이명의 부정적인 영향 (심각성)을 측정하기 위해 개발되었지만, 이명의 자각과 반응을 혼재하여 물어보는 질문으로 구성되어 있었다. 이러한 이명의 자극과 반응에 대한 평가는 객관적으로 측정이 어려우며, 이명 은 주관적인 소리이기 때문에 이명이 있는 사람의 상태를 특징 짓기 위해서는 자가 응답 설문지가 필요하다. 이명의 불편함을 알아보기 위해 가장 널리 사용되는 설문지는 이명장애척도 설 문지(Tinnitus Handicap Inventory, THI)로 25문항으로 이루어 져 있으며(Newman et al., 1996), THI를 간소화시킨 simplified version of THI 역시 10문항(Newman et al., 2008)으로 구성되 어 있다. 또한 Kuk et al.(1990)이 개발한 이명핸디캡 설문지(tinnitus handicap questionnaire)는 27문항으로 구성되어 있다. 이 명으로 인한 어려움을 파악하기 위한 많은 질문 항목은 이명을 겪고 있는 대상자로 하여금 설문지를 작성하는 동안 이명에 대 해 생각해 내며 스트레스가 가중되고, 바쁜 임상 환경에서 설 
문지를 작성하기에 다소 오랜 시간이 소요되기도 한다. 노인의 경우 다양한 질문에 적절한 응답을 하기에는 질문에 대한 이해 도가 낮아 설문지를 작성하는 데 어려움이 있다. 이러한 문제점 을 보완하고자 Schmidt et al.(2014)은 이명의 규모(magnitude) 라는 독창적인 영역을 고안하여, 이명의 자각을 묻는 3문항으로 구성된 이명규모지수(Tinnitus Magnitude Index, TMI)를 개발 하였다(Schmidt et al., 2014). Schmidt et al.(2014)의 보고에 따 르면, 이명의 규모는 이명이 인지되는 강도를 의미하며 어떤 연 구자들은 “심각성(severity)" 또는 "강도(loudness)"라고 부르기 도 한다. TMI는 이명기능지수(Tinnitus Functional Index, $\mathrm{TFI}$ )를 개발하며 얻은 자료를 회기분석하여 질문 항목을 선택 하였다. TFI는 이명의 심각성과 이명치료효과를 측정하기 위해 고안된 설문지로, 8 개의 하위항목으로 나눠지는 25 개 질문으 로 구성되어 있다(Meikle et al., 2012). 그중 이명의 반응을 최 대한 반영하지 않고 자각만을 반영하는 최종적으로 $\mathrm{TFI}$ 의 침 범(intrusiveness) 항목의 3 개 질문 중 2개 질문과 TFI 최종판 에서는 탈락된 질문 1 개(TMI의 2 번 문항)가 선택되었다.

본 논문의 목적은 영문으로 개발된 TMI를 한국어로 번역하 고 번역된 한국어 설문지의 타당성과 신뢰성을 검증하고자 하 는 데 있다. 설문지의 타당성을 위하여 임상에서 널리 쓰이고 있는 이명장애척도(THI) 설문지와 번역된 한국어 TMI와의 상 관관계를 계산하고, TMI 설문지의 신뢰도를 위하여 Cronbach's $\alpha$ 를 분석하였다.

\section{MATERIALS AND METHODS}

\section{연구 대상}

본 연구는 2016년 1월부터 2017년 10월까지 이명을 주 호소 로 연세의료원 안이비인후과병원 청각검사실을 방문한 환자를 대상으로 하였다. 설문지에 참여한 총 환자는 215 명(여자 120 명, 남자 95명)이였으며 연령은 14세부터 85세까지(평균연령 51세) 였다. 인지능력이 저하되어 스스로 설문지 항목을 이해하지 못 하는 경우, 설문지 항목을 완벽히 채우지 않은 경우는 제외시켰 으며 이해되지 않는 항목에 대해서는 질문하여 충분히 이해하 도록 안내하였다. 내원한 이명 환자 중 정상청력 대상자는 40 명, 난청 대상자는 175 명이었다. 정상청력의 기준은 양이 순음청력 평균 $20 \mathrm{~dB} \mathrm{HL}$ 이내이며 어음명료도(word recognition score, WRS) $100 \%$ 이다. 난청의 정도는 경도난청부터 고도난청까지 다양하였으며 순음청력 평균 오른쪽 $21 \mathrm{~dB} \mathrm{HL}$, 왼쪽 $23 \mathrm{~dB}$ $\mathrm{HL}$ 이었다. 이명이 들리는 방향은 양이 99명, 오른쪽 47명, 왼쪽 65 명이었다. 지난 한 주 동안의 이명을 평가하는 것이므로 설문 지를 작성하는 현재 이명이 없더라도 대상자에 참여시켰으며 평균 작성 시간은 2 분 내외였다. 본 연구는 생명윤리위원회의
허가를 받고 진행하였다(\#HUGSAUD 697128).

\section{청각검사}

이명으로 내원한 모든 환자들은 순음검사, 어음검사, 이명검 사를 받았으며 청각검사는 보정된 청각검사기로 진행되었다. 청 각검사기는 GSI-61 (Grason-Stadler Inc., Eden Prairie, MN, USA), Audiostar (Grason-Stadler Inc.)를 이용하였으며, 헤드폰 은 TDH-51과 TDH-39를 사용하였다. 순음검사는 $0.25,0.5,1$, 2, 3, 4, $8 \mathrm{kHz}$ 에서 시행했으며, 어음검사는 speech reception threshold, WRS, most comfortable level을 측정하였다. 이명검 사는 이명주파수, 이명강도, 최소차폐수준, 잔존억제검사를 시 행하였다.

\section{설문지}

이명으로 인한 스트레스를 측정하기 위해, 새롭게 도입할 TMI 와 기존에 한국에서 이명평가에 가장 널리 사용되었던 THI 설 문지를 모두 작성하도록 하였다. 각 설문지에 대한 설명은 아래 에 자세히 서술하였다.

\section{이명규모지수(Tinnitus Magnitude Index)}

설문지의 번역은 저자에게 이메일로 허락을 받고 진행하였다. $\mathrm{TMI}$ 는 모체의 TFI에서 이명의 인지에 해당하는 다음 3 가지 질 문을 선별하였으며, 그러기 위해 이명으로 인한 정신적인 스트 레스 같은 이명의 반응에 겹치는 질문을 모두 제외시켜 다음과 같은 3 가지 질문을 선별하였다.

1) "지난 한 주 동안, 이명은 얼마나 크게 들렸습니까?"

("Over the past week, how strong or loud was your tinnitus?")

2) "지난 한 주 동안, 깨어 있는 시간 중에 이명을 인지하는 시 간은 몇 \% 정도입니까?” (“Over the past week, what percentage of your time awake were you consciously aware of your tinnitus?”)

3) "지난 한 주 동안, 이명이 얼마나 심각하게 느껴졌습니까?"

(“How severe has your tinnitus been over the past week?") 1 번 질문은 0 (전혀 크지 않았다)부터 10 (매우 크게 들렸다)까 지 숫자로 단계를 나누어서, 해당하는 이명의 크기 단계를 선택 하는 것이다. 2 번 질문은 $0 \%$ (전혀 인지하지 않았다)부터 $100 \%$ (항상 인지했다)까지 $10 \%$ 단위로 커지는 숫자 단계를 이용하 여, 깨어 있는 시간 중 이명을 인지하는 시간을 퍼센트로 계산 하여 선택하는 것이다. 3 번 질문은 응답자가 이명을 얼마나 심 하게 느꼈는지, $100 \mathrm{~mm}$ 줄 위에 해당하는 정도를 체크하는 것 이다. 점수는 $0 \mathrm{~mm}$ (전혀 심각하지 않았다)부터 $100 \mathrm{~mm}$ (매우 심각하다고 느꼈다)까지 선 위에 체크한 지점을 $\mathrm{mm}$ 로 측정하 
였다(Appendix). 영어가 원문인 질문을 한국어로 번역하면 원 문과의 의미 차이가 발생할 수 있으므로 2 개 국어(영어, 한국 어)를 사용하며 미국에서 박사학위를 받은 청각전문가 2명이 함께 번역하였다. 또한 번역된 한국어를 다시 거꾸로 영어로 번 역해 보며 원문의 의미와 최대한 가깝게 번역하고자 하였다.

\section{이명장애척도 설문지(Tinnitus Handicap Inventory)}

$\mathrm{THI}$ 는 이명으로 인한 불편함을 측정하는 자가 설문지로 가 장 널리 이용되고 있다. THI는 2가지 버전이 있는데 초기 alpha 버전(45개 질문)과 alpha 버전에서 25개 질문으로 추린 beta 버 전이 있다. 임상에서는 빠르고 쉽게 설문지를 작성할 수 있는 beta 버전이 사용되며, 본 연구에서도 beta-THI를 이용하였다. 앞서 설명한 바와 같이 $\mathrm{THI}$ 는 25 개 질문으로 구성되어 있고 이 질문들은 3 개 하위척도로 나눠진다. 기능(function) 척도는 11 개의 질문, 감정(emotion) 척도는 9개의 질문, 재앙(catastrophe) 척도는 5 개의 질문으로 구성되어 있다.

질문에 대한 응답은 아니다(0점)/조금 그렇다(2점)/그렇다(4 점) 3 가지 중에 고르며 각 질문마다 점수를 합산하여 총 합계 를 구한다. 총 합계가 0 16점까지는 경미함(normal), 18 36점 까지는 약함(mild), 38 56점까지는 보통(moderate), 58 76점 까지는 심함(severe), 78 100점까지는 극심함(catastrophe)으로 분류한다.

\section{통계 분석}

통계분석은 SPSS statistics 21 (IBM Corp., Armonk, NY, USA)을 이용하였다. 첫째, 대상자의 청력 및 이명도 결과와, 둘 째, TMI와 THI의 결과에 대한 기술통계(descriptive statistics) 를 계산하였다. 셋째, $\mathrm{TMI}$ 와 $\mathrm{THI}$ 의 각 문항 간의 상관관계를 알기 위해 Spearman's rank-order correlation을 시행하였다. 넷째, TMI의 내적 일관성(internal consistency)을 구하기 위해 Cronbach's $\alpha$ 를 분석하였으며 또한 그중 항목 1개씩을 제외하 여 $\alpha$ 값을 분석하였다. $P$ 값이 0.01 보다 작을 때 통계적으로 유 의하며 별표 2개로 표시되었고, $\alpha$ 값이 0.7보다 클 때 내적 일 관성을 충족하는 것으로 간주하였다(Cronbach, 1951).

\section{RESULTS}

\section{대상자의 청력 및 이명도 결과}

본 연구는 이명을 주 호소로 연세의료원 이비인후과에 내원 한 215명을 대상으로 진행하였으며 정상청력은 40 명, 난청은 175 명이었다. 성 비율은 남성 95 명, 여성 120 명이며 평균나이는 51 세이다. 이명이 들리는 방향은 오른쪽 47 명, 왼쪽 65 명, 양이 99명이며 평균 순음역치는 오른쪽 $21 \mathrm{~dB} \mathrm{HL}$, 왼쪽 $23 \mathrm{~dB} \mathrm{HL}$
이다(Table 1).

전체 대상자 215 명 중 검사 당시 이명이 들려 이명검사를 시 행한 인원은 86명이며 이명이 들리는 귀의 개수는 112 귀였다. 이명의 음조 매칭 결과 이명 소리의 종류는 협대역잡음(narrow band noise) 46명, 순음(pure tone) 66명이었으며 이명 주파수 는 $8 \mathrm{kHz}$ 가 26명으로 가장 많았다. 잔존억제검사 결과, 이명 크 기에 변화가 있다고 응답한 대상자는 49명이었으며 다시 원래 크기로 돌아올 때까지 평균시간은 53초 소요되었다(Table 2).

\section{TMI 및 $\mathrm{THI}$ 결과}

$\mathrm{TMI}$ 는 1 번 문항의 경우 10 점 척도로, 2 번 문항은 $10 \%$ 단위 로 10 개의 척도에서 대상자가 선택하는 방식이며, 3 번 문항은 $100 \mathrm{~mm}$ 의 선에서 대상자가 자신이 느끼는 대로 선택하고 연구 자가 자로 척도를 측정하였다. 설문지는 $\mathrm{THI}$ 와 $\mathrm{TMI}$ 를 사용하 였으며 각각의 평균 점수는 Table 3 과 같다.

$\mathrm{TMI}$ 각 질문별 평균은 1 번 문항 5 점, 2 번 문항 60 점, 3 번 문 항 53점이었으며 $\mathrm{THI}$ 질문을 성격별로 나눈 하위척도의 평균 은 기능척도는 19점, 감정척도는 14점, 재앙척도는 8점으로 합계 평균은 41점이었다. THI 합계를 점수별로 정상(normal), 약함 (mild), 보통(moderate), 심함(severe), 극심함(catastrophe)의 5 개 그룹으로 나눌 수 있으며 각 그룹별 분포는 33명, 78명, 49명, 29 명, 26명으로 약함에 속하는 그룹의 대상자가 제일 많았으며 극심함에 속하는 그룹의 대상자의 수가 제일 적었다.

\section{$\mathrm{TM}$ 와 $\mathrm{TH}$ 와의 상관관계}

$\mathrm{TMI}$ 각 질문 항목이 THI의 어떤 하위척도와 연관 있는지 알 기 위하여 TMI 각 질문과 THI 하위척도 및 총합 간의 Spearman's rank-order 상관관계를 분석하였으며 결과는 Table 4에 기재하였다. TMI와 THI 총합은 중등도 상관관계 $\left(\mathrm{r}_{\mathrm{s}}=0.403\right.$ $0.530, p<0.001)$ 를 보이며, TMI의 각 질문별 $\mathrm{THI}$ 하위척도별 역시 중등도 상관관계를 보였다 $\left(\mathrm{r}_{\mathrm{s}}=0.255 \sim 0.562, p<0.001\right)$.

Table 1. Characteristics of participants $(n=215)$

\begin{tabular}{cc}
\hline Characteristics & \\
\hline Gender & Number of subjects \\
\hline Female & 120 \\
Male & 95 \\
\hline Tinnitus ear & Number of ears \\
\hline Right & 47 \\
Left & 65 \\
Both & 99 \\
\hline PTA & Mean \pm SD \\
\hline Right & $21 \pm 14.6 \mathrm{~dB} \mathrm{HL}$ \\
Left & $23 \pm 17.1 \mathrm{~dB} \mathrm{HL}$ \\
\hline
\end{tabular}

SD: standard deviations, PTA: pure tone average 
$\mathrm{THI}$ 기능(function)에 해당하는 문항과 TMI 질문과 가장 상 관관계가 높은 것으로 나타났다.

$\mathrm{TMI}$ 와 THI 각 질문 항목끼리의 상관계수는 Table 5 에 기재 하였다. Spearman's rank-order 상관계수는 0.165부터 0.532까 지 다양하게 분포되어 있으며 THI 1번 문항(“이명 때문에 집중 하기가 어렵습니까?")이 TMI 1번 문항 $\left(\mathrm{r}_{\mathrm{s}}=0.493, p<0.001\right)$, TMI 2번 문항 $\left(\mathrm{r}_{\mathrm{s}}=0.471, p<0.001\right)$, TMI 3번 문항 $\left(\mathrm{r}_{\mathrm{s}}=0.532\right.$, $p<0.001$ 과 상관관계가 가장 높았다. 그중 TMI 3번 문항(“지 난 한 주 동안, 이명이 얼마나 심각하게 느껴졌습니까")과 $\mathrm{THI}$ 1 번 문항의 상관계수가 가장 높았다.

Table 2. Tinnitogram results of subjects

\begin{tabular}{|c|c|}
\hline Characteristics & \\
\hline Side & Number of ears \\
\hline Both & 41 \\
\hline Left & 26 \\
\hline Right & 19 \\
\hline Type of tinnitus sound & Number of ears \\
\hline NBN & 46 \\
\hline Pure tone & 66 \\
\hline Frequency $(\mathrm{kHz})$ & Number of ears \\
\hline 0.125 & 5 \\
\hline 0.25 & 5 \\
\hline 0.5 & 8 \\
\hline 0.75 & 2 \\
\hline 1 & 17 \\
\hline 1.5 & 1 \\
\hline 2 & 12 \\
\hline 3 & 5 \\
\hline 4 & 16 \\
\hline 6 & 11 \\
\hline 8 & 28 \\
\hline 12 & 2 \\
\hline Residual inhibition & Number of ears \\
\hline Softer & 18 \\
\hline Louder & 5 \\
\hline No change & 63 \\
\hline Disappear & 26 \\
\hline Tinnitus loudness and masking level & Mean (dB HL) \\
\hline Tinnitus loudness & 39 \\
\hline MML & 34 \\
\hline
\end{tabular}

NBN: Narrowband noise, MML: minimum masking level

\section{TMI의 내적 일관성(Internal consistency)}

TMI 3개 질문의 내적 일관성을 측정하기 위해 Cronbach's $\alpha$ 를 분석하였다. Cronbach's $\alpha$ 는 0.852 로 매우 높게 나왔으며 이

Table 4. Spearman's ranked-order correlation between THI and TMI

\begin{tabular}{llllc}
\hline & THI-F & THI-E & THI-C & THI-sum \\
\hline $\mathrm{TMI}_{1}$ & $0.562^{* *}$ & $0.475^{* *}$ & $0.333^{* *}$ & $0.530^{* *}$ \\
$\mathrm{TMI}_{2}$ & $0.455^{* *}$ & $0.327^{* *}$ & $0.255^{*}$ & $0.403^{* *}$ \\
$\mathrm{TMI}_{3}$ & $0.522^{* *}$ & $0.446^{* *}$ & $0.334^{* *}$ & $0.503^{* *}$ \\
\hline
\end{tabular}

${ }^{*} p<0.1,{ }^{* *} p<0.05$. THI: Tinnitus Handicap Inventory, TMI: Tinnitus Magnitude Index, THI-F: THI-function, THI-E: THI-emotion, THI-C: THI-catastrophe, THI-sum: THI-summation, $\mathrm{TMI}_{1}$ : TMI No. 1 question, $\mathrm{TMI}_{2}$ : TMI No. 2 question, $\mathrm{TMI}_{3}$ : TMI No. 3 question

Table 5. Spearman's rank-order correlation between TMI and THI total item

\begin{tabular}{|c|c|c|c|}
\hline & $\mathrm{TMI}_{1}$ & $\mathrm{TMI}_{2}$ & $\mathrm{TMI}_{3}$ \\
\hline THI 1 & $0.493^{* *}$ & $0.471^{* *}$ & $0.532^{* *}$ \\
\hline THI 2 & $0.339 * *$ & $0.338^{* *}$ & $0.319^{* *}$ \\
\hline THI 3 & $0.377^{* *}$ & $0.208^{* *}$ & $0.371^{* *}$ \\
\hline THI 4 & $0.301^{* *}$ & $0.192^{* *}$ & $0.291^{* *}$ \\
\hline THI 5 & $0.311^{* *}$ & $0.181^{* *}$ & $0.322^{* *}$ \\
\hline THI 6 & $0.394^{* *}$ & $0.311^{* *}$ & $0.402^{* *}$ \\
\hline THI 7 & $0.346^{* *}$ & $0.214^{* *}$ & $0.338^{* *}$ \\
\hline THI 8 & $0.244^{* *}$ & $0.200^{* *}$ & $0.281^{* *}$ \\
\hline THI 9 & $0.407^{* *}$ & $0.347^{* *}$ & $0.364^{* *}$ \\
\hline THI 10 & $0.313^{* *}$ & $0.233^{* *}$ & $0.331^{* *}$ \\
\hline THI 11 & $0.206^{* *}$ & $0.203^{* *}$ & $0.173^{*}$ \\
\hline THI 12 & $0.350^{* *}$ & $0.325^{* *}$ & $0.385^{* *}$ \\
\hline THI 13 & $0.335^{* *}$ & $0.308^{* *}$ & $0.280^{* *}$ \\
\hline THI 14 & $0.395^{* *}$ & $0.253^{* *}$ & $0.359^{* *}$ \\
\hline THI 15 & $0.338^{* *}$ & $0.230^{* *}$ & $0.234^{* *}$ \\
\hline THI 16 & $0.410^{* *}$ & $0.214^{* *}$ & $0.326^{* *}$ \\
\hline THI 17 & $0.358^{* *}$ & $0.317^{* *}$ & $0.359^{* *}$ \\
\hline THI 18 & $0.402^{* *}$ & $0.312^{* *}$ & $0.378^{* *}$ \\
\hline THI 19 & $0.223^{* *}$ & $0.178^{* *}$ & $0.216^{* *}$ \\
\hline THI 20 & $0.460^{* *}$ & $0.381^{* *}$ & $0.432^{* *}$ \\
\hline THI 21 & $0.398^{* *}$ & $0.330^{* *}$ & $0.374^{* *}$ \\
\hline THI 22 & $0.276^{* *}$ & $0.169^{*}$ & $0.256^{* *}$ \\
\hline THI 23 & $0.242^{* *}$ & $0.194^{* *}$ & $0.250^{* *}$ \\
\hline THI 24 & $0.285^{* *}$ & $0.165^{*}$ & $0.184^{* *}$ \\
\hline THI 25 & $0.420^{* *}$ & $0.271^{* *}$ & $0.386^{* *}$ \\
\hline
\end{tabular}

${ }^{*} p<0.1,{ }^{* *} p<0.05$. TMI: Tinnitus Magnitude Index, THI: Tinnitus Handicap Inventory, $\mathrm{TMI}_{1}$ : TMI No. 1 question, $\mathrm{TMI}_{2}$ : TMI No. 2 question, $\mathrm{TMI}_{3}$ : TMI No. 3 question

Table 3. Averages and SDs of TMI and THI

\begin{tabular}{|c|c|c|c|c|c|c|c|}
\hline \multirow{2}{*}{ Score } & \multicolumn{3}{|c|}{ TMI } & \multicolumn{4}{|c|}{ THI } \\
\hline & $\mathrm{TMI}_{1}$ & $\mathrm{TMI}_{2}$ & $\mathrm{TMI}_{3}$ & Function & Emotion & Catastrophe & Total \\
\hline Average $\pm S D$ & $5 \pm 2.5$ & $60 \pm 32.4$ & $53 \pm 27.4$ & $19 \pm 11.7$ & $14 \pm 9.1$ & $8 \pm 5.5$ & $41 \pm 23.9$ \\
\hline
\end{tabular}

SD: standard deviation, TMI: Tinnitus Magnitude Index, TMI : TMI No. 1 question, $\mathrm{TMI}_{2}$ : TMI No. 2 question, TMI : TMI No. 3 question, THI: Tinnitus Handicap Inventory 
는 원문(영어) 설문지(Cronbach's $\alpha=0.86)$ 와 비슷한 수치이다. 3 가지 항목 중 1 가지가 삭제되었을 경우 내적 일관성이 어떻게 변하는지 알기 위해 항목 제거 시 척도 역시 분석해 보았다. TMI 1 번 문항 또는 3 번 문항이 삭제될 경우 내적 일관성은 감소하였 으며 $(\alpha=0.804$ 그리고 $\alpha=0.698)$, TMI 2 번 문항이 삭제될 경 우 내적 일관성은 약간 증가하였다 $(\alpha=0.883)$.

\section{DISCUSSIONS}

본 연구의 목적은 영문으로 개발된 TMI 설문지를 한국어로 번역하고 번역한 한국어 설문지에 대한 타당도 및 신뢰도를 검 증하고자 하였다. 타당도를 위해서는 임상에서 널리 사용하고 있는 THI와의 상관관계를 계산하였으며, 신뢰도를 위해서는 $\mathrm{TMI}$ 의 각 문항당 Cronbach's $\alpha$ 값을 분석하였다.

$\mathrm{TMI}$ 의 각 항목과 THI의 합계를 Spearman's rank-order 상 관분석한 결과 $\left(\mathrm{TMI} 1\right.$ 번 질문 $\mathrm{r}_{\mathrm{s}}=0.530, \mathrm{TMI} 2$ 번 질문 $\mathrm{r}_{\mathrm{s}}=$ 0.403 , TMI 3번 질문 $r_{s}=0.503$ )는 Schmidt et al.(2014)에 의한 연구결과(TMI 1번 질문 $\mathrm{r}_{\mathrm{s}}=0.54$, TMI 2번 질문 $\mathrm{r}_{\mathrm{s}}=0.47$, TMI 3 번 질문 $\left.r_{s}=0.64\right)$ 와 유사하게 중간 정도 상관관계를 보였다. 본 연구와 이전 연구의 결과 3 번 항목의 Spearman's rank-order 상관계수가 가장 큰 차이를 보이며 3번 항목은 보기가 주어지는 폐쇄형(closed-set) 응답 형식이 아닌 시각적 아날로그 스케일로 응답자의 주관성이 가장 많이 포함되는 질문이다. Schmidt et al.(2014)의 연구에서는 TMI의 각 항목과 THI의 합계만을 비교 하였지만 본 연구에서는 THI와의 더 정확한 비교를 위해 첫째, $\mathrm{TMI}$ 각 항목과 THI 각 항목별, 둘째, THI 하위척도(기능, 감 정, 재앙)와의 Spearman's rank-order 상관관계를 분석하였다.

첫째로, TMI 각 항목이 THI의 어떤 질문과 상관성이 있는지 분석 결과, TMI 모든 질문은 THI 1번 질문과 가장 상관성이 높 게 나왔다: TMI 1 번 문항 $\left(\mathrm{r}_{\mathrm{s}}=0.493\right), \mathrm{TMI} 2$ 번 문항 $\left(\mathrm{r}_{\mathrm{s}}=0.471\right)$, TMI 3번 문항 $\left(\mathrm{r}_{\mathrm{s}}=0.532\right)$. THI 1번 문항(“이명 때문에 집중하 기가 어렵습니까?”)은 하위척도 중 기능척도에 해당한다. 둘째, $\mathrm{TMI}$ 와 $\mathrm{THI}$ 하위척도와의 상관관계 결과 $\mathrm{TMI}$ 의 모든 질문은 $\mathrm{THI}$ 기능척도와 상관관계가 높고, TMI 1 번 문항 $\left(\mathrm{r}_{\mathrm{s}}=0.554, p<\right.$ $0.001)$, TMI 2번 문항 $\left(\mathrm{r}_{\mathrm{s}}=0.446, p<0.001\right)$, TMI 3번 문항 $\left(\mathrm{r}_{\mathrm{s}}=\right.$ $0.509, p<0.001)$, 재앙척도와 가장 낮은 상관관계를 나타내었 다. THI 기능척도는 이명으로 인한 정신적, 사회적, 직업적, 신 체적 제약을 반영하며, 재앙척도는 이명에 의한 환자의 절망감 을 반영하는 척도이다(Newman et al., 1996). 이는 TMI가 이 명에 의한 반응(감정적 고통, 집중력 저하, 자제능력 저하, 수면 방해 등)보다는 자각을 더 많이 반영한다는 사실을 알 수 있다.

이전 연구에서는 TMI의 각 질문별 통계분석만 하였으나 본 연구에서는 $\mathrm{TMI}$ 점수 합산과 $\mathrm{THI}$ 점수 합산 간의 관계를 알
아보고자 하였다. THI 점수 합산은 0 100점 사이이므로 TMI 점수합산 역시 0 100점 사이로 하기 위하여 TMI 각 질문 항 목당 점수에 가중치(weight)를 곱하여 점수 범위를 동일하게 설정하였다. TMI 항목 3 개에 동일한 가중치를 적용하는 것이 아니라 질문의 중요도에 따라 가중치를 다르게 설정하였다. TMI 내적 일관성을 Cronbach's $\alpha$ 로 시행하였을 때 2번 항목 제거 시 $\alpha$ 값이 증가하였고 이는 2번 항목이 다른 항목들에 비 해 일관되게 측정하지 못한다는 의미이며, THI 점수 합계가 증 가함에 따라 TMI 2번 항목 역시 일관되게 증가하는 것이 아니 라 THI와의 오차범위가 매우 넓었다(Figure 2). 2번 항목에서 100 점을 선택한 사람은 56 명으로 1,3 번에서 100 점을 선택한 사람(각 16 명, 18 명)에 비해 매우 많았는데 이는 응답이 과장되 거나 감정적으로 반응한 부분이 오염되었다는 의미이다. 따라 서 2 번 항목의 가중치를 가장 작게 설정해야겠다는 예측을 할 수 있으며, 앞으로 질문을 수정하거나 이명에 대한 인지를 반영 하는 다른 질문으로 대체할 필요가 있다.

Figure 3에서 보면 연구대상자를 THI 합계 오름차순으로 재 정렬하여 $\mathrm{THI}$ 와 $\mathrm{TMI}$ 증가 추세를 나타내었다. THI가 증가할 수록 TMI 3가지 항목 점수도 양적으로 모두 증가하긴 하지만 증가하는 비율이 항목마다 다르며, THI와 오차를 가장 줄일 수 있는 TMI 항목별 가중치(weight)를 MATLAB 프로그램 (MathWorks Inc., Natick, MA, USA)을 이용해 구하였다(Figure 3).

가중치를 구하는 수식은 다음과 같다.

$\mathrm{x}=\mathrm{TMI}_{1} \times \mathrm{a}+\mathrm{TMI}_{2} \times \mathrm{b}+\mathrm{TMI}_{3} \times \mathrm{c}$

( $a, b, c=$ weight, $0 \leq a, b, c \leq 1 \& a+b+c=1)$

$\mathrm{x}$ 는 TMI의 합계이며 a, b, c는 TMI 각 항목의 가중치를 의 미한다.

$\mathrm{TMI}_{1}, \mathrm{TMI}_{2}, \mathrm{TMI}_{3}$ 과 $\mathrm{x}$ 를 모두 같은 범위로 맞추기 위하여 $\mathrm{a}, \mathrm{b}, \mathrm{c}$ 합은 1 이 된다.

변수의 숫자를 줄이기 위하여 수식을 변형하면 다음과 같다.

$$
\begin{aligned}
& \mathrm{x}=\mathrm{TMI}_{1} \times \alpha+\mathrm{y} \times(1-\alpha) \\
& \mathrm{y}=\mathrm{TMI}_{2} \times(1-\beta)+\mathrm{TMI}_{3} \times \beta(0 \leq \alpha, \beta \leq 1) \\
& \therefore \mathrm{x}=\mathrm{TMI}_{1} \times \alpha+\mathrm{TMI}_{3} \times(1-\alpha) \beta+\mathrm{TMI}_{2} \times(1-\alpha)(1-\beta)
\end{aligned}
$$

연구 대상자 215 명의 $\mathrm{TMI}$ 와 $\mathrm{THI}$ 합계 차이의 절대값을 모 두 더한 값이 $\delta$ 이며, $\delta$ 값을 최소화하는 $\alpha, \beta$ 값을 Figure 4에 동그라미로 표시하였다. 

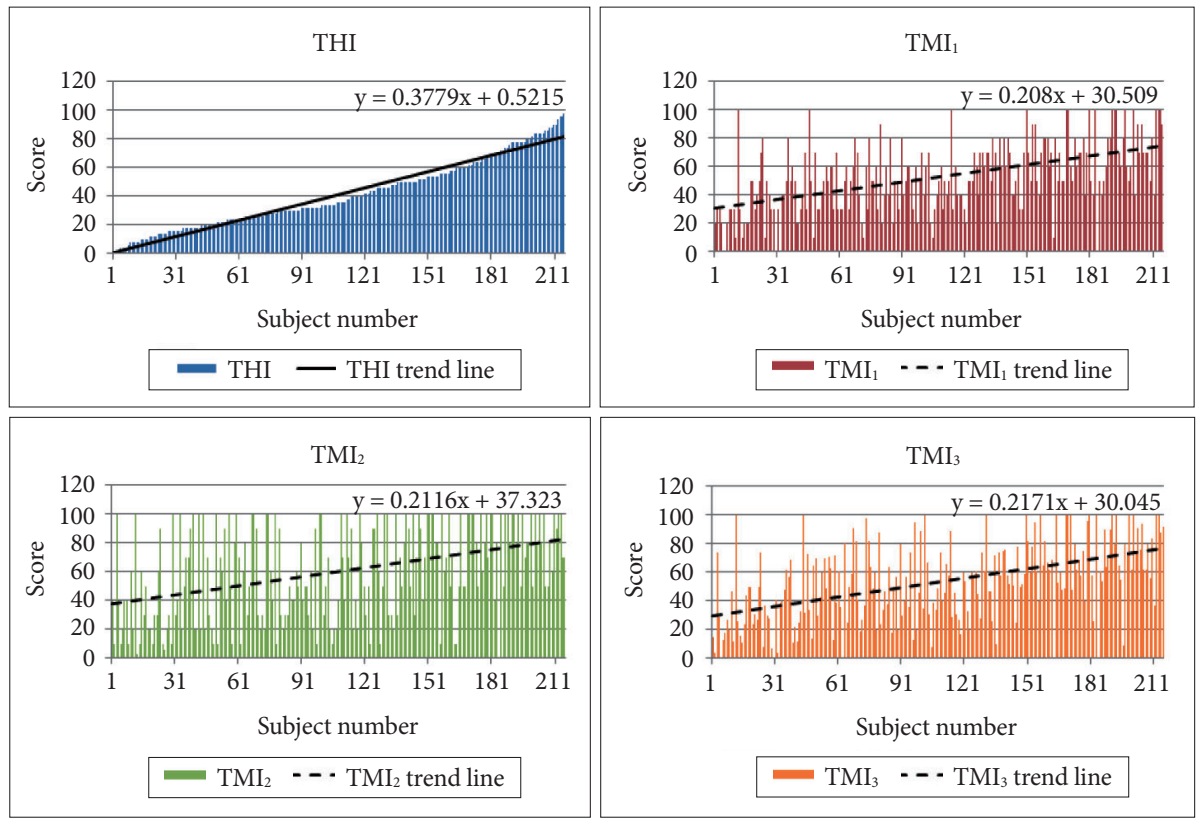

Figure 2. Increase trend of TMI score according to $\mathrm{THI}$ score. 215 subjects were reordered in ascending order of $\mathrm{THI}$ summation, and the trend of increasing score by TMI item was compared. THI: Tinnitus Handicap Inventory, TMI: Tinnitus Magnitude Index, TMl: TMI No. 1 question, $\mathrm{TMl}_{2}$ : TMI No. 2 question, $\mathrm{TMl}_{3}$ : TMI No. 3 question.

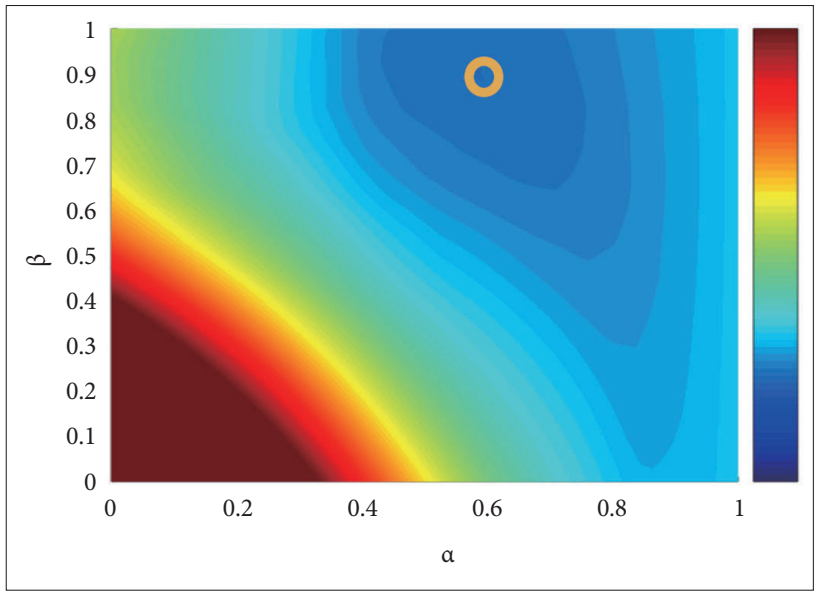

Figure 3. Absolute errors of Tinnitus Magnitude Index summation to Tinnitus Handicap Inventory summation. Delta values according to alpha, beta values are displayed by color.

$$
\delta=\sum_{\mathrm{i}=1}^{215} \mid \mathrm{x}_{\mathrm{i}}-\text { THI_sum } \mathrm{i} \mid
$$

그 결과 TMI 질문별 가중치는 1번: 0.5856, 2번: 0.0423, 3번: 0.3721 이다.

가중치를 적용하여 $\mathrm{TMI}$ 점수를 합산한 결과 $\mathrm{THI}$ 와의 오차 가 가장 줄어들며 THI와의 추세선 기울기가 가장 비슷해졌다 (Figure 4). 또한 TMI 합계와 THI 합계를 Spearman's rankorder 상관분석하였을 때 가중치 없는 단순 평균값 $\left(\mathrm{r}_{\mathrm{s}}=0.535\right)$ 보다 가중치를 적용한 값 $\left(\mathrm{r}_{\mathrm{s}}=0.553\right)$ 에서 상관계수가 약간 증 가하였다(Table 6). 이는 TMI와 THI와의 오차를 최소한으로 줄여도 둘 사이의 Spearman's rank-order 상관계수는 0.553이 최고라는 의미이다.

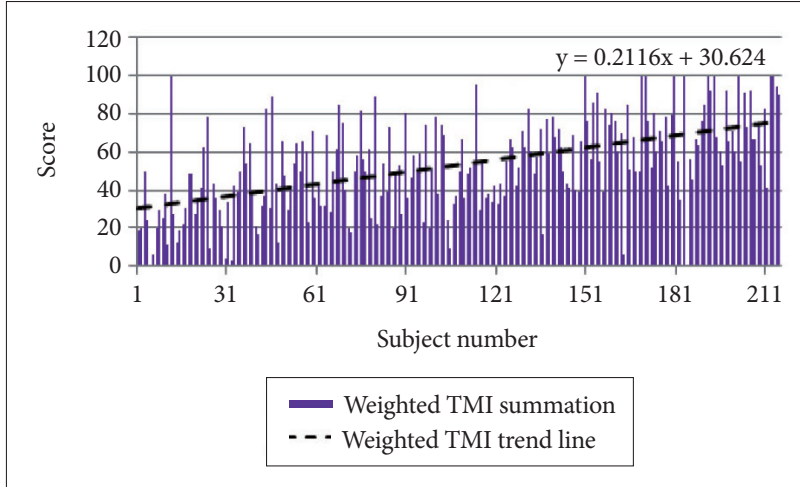

Figure 4. Increase trend of weighted TMI summation score according to THI score. 215 subjects were reordered in ascending order of THI summation, and the trend of increasing score by weighted TMI summation was compared. TMI: Tinnitus Magnitude Index, THI: Tinnitus Handicap Inventory.

Table 6. Spearman's rank-order correlation between THI sum and weighted \& unweighted TMI sum

\begin{tabular}{lcc}
\hline & \multicolumn{2}{c}{ TMI } \\
\cline { 2 - 3 } & Weighted sum & Unweighted sum \\
\hline THI sum & $0.553^{*}$ & $0.535^{*}$ \\
\hline${ }^{*} p<0.01$. THI: Tinnitus Handicap & Inventory, TMI: Tinnitus Mag-
\end{tabular}
nitude Index, sum: summation

$\mathrm{TMI}$ 와 $\mathrm{THI}$ 의 차이점은 $\mathrm{TMI}$ 는 이명의 자각만을 측정하며 $\mathrm{THI}$ 는 이명의 자각과 반응을 모두 측정한다는 것이다. 또한 $\mathrm{THI}$ 는 응답자가 그렇다/가끔/아니다 중 하나를 선택하지만 $\mathrm{TMI}$ 는 0 10점(또는 0 100점) 사이 중 정도에 따라 점수를 선 택할 수 있다. 선택지가 세분화되면서 이명을 더 자세하게 측정 할 수 있으며 이는 이명치료 전후 평가에 유용하게 적용될 수 있을 것이다. 또한 $\mathrm{THI}$ 의 질문 중에는 "이명 때문에 종종 짜증 
나는 경우가 있습니까?", "이명 때문에 종종 피곤함을 느끼십니 까?”같이 응답하기 모호한 표현들이 있다. 개인마다 ‘종종'의 기 준이 다르며, 응답 시에도 역시 어느 정도를 '가끔'이라고 선택 해야 할지 혼란스러워하는 경우가 많다. 이와 대조적으로 TMI 의 경우 질문지에 '종종', '몹시'와 같은 모호한 표현이 없으며 응 답도 0 100점(또는 0 10점) 사이 중 정도에 따라 수치를 선택 할 수 있으므로 횔씬 측량적이고 객관적인 지표가 될 수 있다.

$\mathrm{TMI}$ 는 이명으로 인한 반응으로부터 독립적인 이명의 자각 이라는 새로운 영역을 고안했다는 점이 가장 주목할 부분이며, 이명으로 인한 스트레스와 이명의 규모(magnitude)와는 상호 적인 관계를 가지고 있다(Mazurek et al., 2012). TMI와 THI는 이명을 평가하는 방법과 기준이 다르므로 둘 사이의 상관관계 를 통계분석한 결과 중간 정도의 상관관계만 보였지만, 이는 $\mathrm{TMI}$ 의 경우 이명의 양을 자각하는 정도를, $\mathrm{THI}$ 는 이명으로 인한 장애지수를 평가한 것이기에 중도의 상관관계를 가질 수 있다고 본다. 그러나 앞의 서론에서 언급한 바와 같이 $\mathrm{CBT}$ 와 ALT에 의해 이명의 자각만으로도 이명으로 인한 정신적인 불 편함을 예측할 수 있다는 것을 모델링하였고, 본 연구의 결과 를 통해 THI 점수가 높아질수록 TMI 점수도 양적으로 증가하 는 것을 확인하였다. TMI는 $\mathrm{THI}$ 의 기능을 똑같이 반영하면서 문항 수만 감소된 설문지가 아니라, THI와는 다르게 이명의 자 각만을 정량화한 새로운 측면의 설문지이다. 따라서 $\mathrm{THI}$ 와 상 호 보완적으로 사용할 수 있으며, TMI 단독으로도 이명으로 인한 정신적인 불편함을 평가하는 데 매우 유용하게 사용될 수 있을 것이다.

본 연구의 한계점은 한국어 버전 $\mathrm{TMI}$ 를 반복검사하였을 경 우 신뢰도에 대한 연구가 결여되어 있다는 것이다. Schmidt et al.(2014)에 의한 연구 결과에 따르면 TMI는 검사-재검사 신뢰 도 결과에서 만족스러운 통계학적 의미 $\left(\mathrm{r}_{\mathrm{s}}=0.74, \mathrm{df}=29, p<\right.$ $0.001)$ 를 가졌다고 하였으나 한국어 버전에 대한 결과는 향후 연구를 통해 검사-재검사 신뢰를 도출할 필요가 있다. TMI가 이명으로 인한 정신적인 스트레스를 잘 예측할 수 있는지 상태 불안척도(state trait anxiety inventory) (Spielberger et al., 1970)나 벡우울척도(Beck depression inventory) (Beck et al., 1996) 같은 심리적 설문지를 추가하여 상관관계를 분석하면 $\mathrm{TMI}$ 가 다른 이명 설문지와 비교하였을 때 적은 문항으로도 이 명으로 인한 정신적인 스트레스를 잘 예측할 수 있는지 증명될 것이다. 또한 가장 중요하게 정립해야 할 문제는 TMI 문항의 응답척도를 일관되게 바꾸는 것이다. 응답 범위가 1 번 질문은 0 10점, 2번 질문은 0 100점, 3번 질문은 시각적 아날로그 척 도로 대상자가 표시한 곳까지 자로 재어 $\mathrm{mm}$ 단위로 표시한다. 앞으로 TMI 모든 질문의 응답 범위를 일관되게 통일하여 표준 모델을 제시하는 것이 필요하며 TMI 점수 합계에 대한 연구가
더욱 필요할 것이다. TMI 점수 합계가 몇 점 이상일 때 이명치 료가 필요하며, THI 점수별 장애등급처럼 TMI 점수의 합계가 몇 점일 때 이명으로 인한 스트레스가 어느 정도인지 파악할 수 있는 지표에 대한 연구가 후속연구에서 이루어져야 할 것이다.

중심 단어 : 이명·설문지·이명규모지수.

\section{REFERENCES}

Beck, A. T., Steer, R. A., \& Brown, G. K. (1996). Manual for the Beck Depression Inventory-II. San Antonio, TX: Psychological Corporation.

Cima, R. F., Vlaeyen, J. W., Maes, I. H., Joore, M. A., \& Anteunis, L. J. (2011). Tinnitus interferes with daily life activities: A psychometric examination of the Tinnitus Disability Index. Ear and Hearing, 32(5), 623-633.

Cronbach, L. J. (1951). Coefficient alpha and the internal structure of tests. Psychometrika, 16(3), 297-334.

Dobie, R. A. (2004). Overview: Suffering from tinnitus. In Snow, J. B. Jr. Tinnitus: Theory and Management (pp. 1-7). Hamilton, ON: BC Decker.

Hear-it. (2018, April, 14). Prevalence of tinnitus. Hear-it. Retrieved from https://www.hear-it.org/prevalence-tinnitus.

Helson, H. (1964). Adaptation-Level Theory: An Experimental and Systematic Approach to Behavior. (1st ed.). New York, NY: Harper and Row.

Henry, J. L. \& Wilson, P. H. (2000). The Psychological Management of Chronic Tinnitus: A Cognitive-Behavioral Approach. (1st ed.). Boston, MA: Allyn \& Bacon.

Jun, H. J., Yoo, I. W., Hwang, S. J., \& Hwang, S. Y. (2015). Validation of a Korean version of the Tinnitus Handicap Questionnaire. Clinical and Experimental Otorhinolaryngology, 8(3), 198-201.

Kuk, F. K., Tyler, R. S., Russell, D., \& Jordan, H. (1990). The psychometric properties of a tinnitus handicap questionnaire. Ear and Hearing, 11(6), 434-445.

Lee, S. Y., Kim, J. H., Hong, S. H., \& Lee, D. S. (2004). Roles of cognitive characteristics in tinnitus patients. Journal of Korean Medical Science, 19(6), 864-869.

Mazurek, B., Haupt, H., Olze, H., \& Szczepek A. J. (2012). Stress and tinnitus-from beside to bench and back. Frontiers in Systems Neuroscience, 6 , 47.

McCormack, A., Edmondson-Jones, M., Somerset, S., \& Hall, D. (2016). A systematic review of the reporting of tinnitus prevalence and severity. Hearing Research, 337, 70-79.

Meikle, M. B., Henry, J. A., Griest, S. E., Stewart, B. J., Abrams, H. B., McArdle, R., et al. (2012). The tinnitus functional index: Development of a new clinical measure for chronic, intrusive tinnitus. Ear and Hearing, 33(2), 153-176.

Meikle, M. B., Stewart, B. J., Griest, S. E., \& Henry, J. A. (2008). Tinnitus outcomes assessment. Trends in Amplification, 12(3), 223-235.

Møller, A. R. (2007). Tinnitus and pain. Progress in Brain Research, 166, 4753.

Newman, C. W., Jacobson, G. P., \& Spitzer, J. B. (1996). Development of the tinnitus handicap inventory. Archives of Otolaryngology-Head and Neck Surgery, 122(2), 143-148.

Newman, C. W., Sandridge, S. A., \& Bolek, L. (2008). Development and psychometric adequacy of the screening version of the tinnitus handicap inventory. Otology and Neurotology, 29(3), 276-281.

Rudy, T. E., Kerns, R. D., \& Turk, D. C. (1988). Chronic pain and depression: Toward a cognitive-behavioral mediation model. Pain, 35(2), 129140.

Schmidt, C. J., Kerns, R. D., Griest, S., Theodoroff, S. M., Pietrzak, R. H., \& Henry, J. A. (2014). Toward development of a tinnitus magnitude index. Ear and Hearing, 35(4), 476-484.

Searchfield, G. D., Kobayashi, K., \& Sanders, M. (2012). An adaptation level theory of tinnitus audibility. Frontiers in Systems Neuroscience, 6, 46. 
Spielberger, C. D., Gorsuch, R. L., \& Lushene, R. E. (1970). The State-Trait Anxiety Inventory (S T A I): Test Manual for Form X. (1st ed.). Palo Alto, CA: Consulting Psychologists Press.

Stouffer, J. L. \& Tyler, R. S. (1990). Characterization of tinnitus by tinnitus patients. The Journal of Speech and Hearing Disorders, 55(3), 439-453 Tyler, R. S. \& Baker, L. J. (1983). Difficulties experienced by tinnitus sufferers. The Journal of Speech and Hearing Disorders, 48(2), 150-154. 


\section{APPENDIX}

Korean version of Tinnitus Magnitude Index

1. 지난 한 주 동안, 이명이 얼마나 크게 들렸습니까? 가장 적절한 곳에 동그라미 표시를 하십시오 (0번: 전혀 크지 않았다, 10번: 매우 크게 들렸다).

$\begin{array}{lllll}0 & 1 & 2 & 3 & 4\end{array}$

5

6

7

8

9

10

(전혀 크지 않았다)

(매우 크게 들렸다)

2. 깨어 있는 시간 중에 이명을 인지하는 시간은 몇 \% 정도 되었습니까? 가장 적절한 곳에 동그라미 표시를 하십시오 (0\%: 이명을 전혀 인지하지 못했다, $100 \%:$ 이명을 항상 인지하였다).

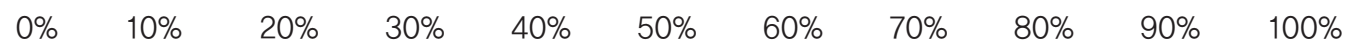

(전혀 인지하지 못하였다)

(항상 인지하였다)

3. 지난 한 주 동안, 이명이 얼마나 심각하게 느껴졌습니까? 해당하는 곳에 X 표시 하십시오 (0: 전혀 심각하지 않았다, 100: 매우 심각하다고 느꼈다).

(전혀 심각하지 않았다)

(매우 심각하다고 느꼈다) 